\title{
BDSA Conference 2020: Review
}

\section{By Nazgol Mashaikhirad, BDSA Conference Organiser, and Richa Tore, BDSA Communications Officer}

On Friday 6 March 300 dental students from universities across the UK descended on Barts and the London for the annual BDSA Conference.

With over 20 stands at the Trade Fayre, delegates had the opportunity to engage with different companies, societies and organisations. Students were able to find out more about indemnity advice, try loupes from a range of companies and, of course, get many, many coveted freebies. Two that stick in my mind were Smile Dental Academy who had their own DJ and Red Oak Roller who were giving away free T-shirts to attendees.

The next two days consisted of lectures delivered by renowned specialists designed to give delegates an idea of what the profession really entails. This is the beauty of the BDSA Conference - it allows students to explore subjects outside of the main curriculum we may not have heard about or have an interest in.

This year, topics ranged from endodontics to mindfulness and altruism. Delegates were introduced to Mercy Ships, an international charity who provide medical relief in Africa. Dr Vaghela and Dr Chohan, part of Smile Dental Academy, gave helpful DFT tips, advice on how to handle difficult interviews and useful acronyms to utilise whilst studying. In addition, they offered students the chance to shadow them in practice, which is pretty amazing and a reason to attend the conference on its own. There were also amazing prizes available - wireless apex locators, loupes vouchers to name but a few. Students gained

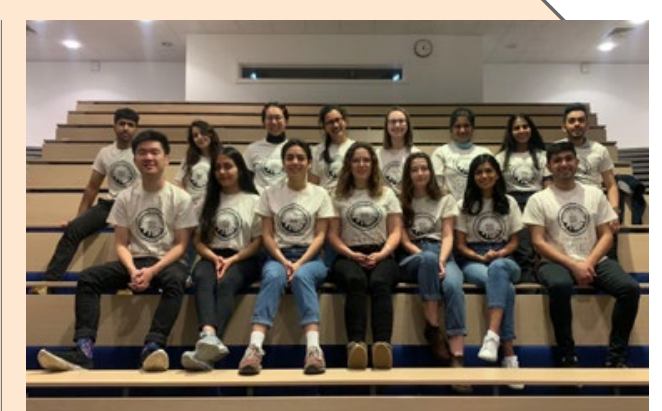

a real insight into life after dental school and how they can plan for the future as they embark on the next stage in their careers.

For those of you who haven't ever attended one, the weekend isn't complete without the infamous social events. From t-shirt night, fancy dress night and the grand finale - the spectacular 'Casino Royale' ball - there's something for everyone.

Follow@bdsaofficial on Instagram for the latest updates on BDSA events, including details of the annual Sports Day later this year.

Nazgol Mashaikhirad

\section{DENTISTRY AT KING'S COLLEGE LONDON 1ST IN THE WORLD}

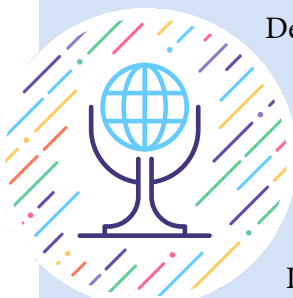

Dentistry at King's College London has been ranked first in the world in the QS World University Rankings 2020.

The faculty has consistently placed first in the UK since 2017, but the 2020 ranking marks a significant new high for the faculty.

Indeed, one never achieved by a King's College

London faculty before. The latest result illustrates the exceptional quality of the research and education performed at King's Faculty of Dentistry, Oral \& Craniofacial Sciences. Shaped by a diverse student and staff population which adds strength to the faculty standing, this latest ranking confirms their position as a world-class institution.

Professor Mike Curtis, Executive Dean of the Faculty of Dentistry, Oral \& Craniofacial Sciences, said: 'The faculty is obviously delighted to receive this accolade. I would personally like to thank all members of staff and all our students whose dedication and abilities are responsible for this notable achievement.'

Professor Sir Robert Lechler Provost/Senior Vice President (Health) of King's College London added: 'This achievement recognises the major contribution of the faculty to the research base of dentistry, and the high quality of education and career preparation provided to our students, under the skilled leadership of Professor Mike Curtis. Congratulations to all.'

\section{Branches and Sections}

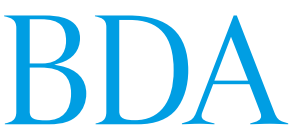

British Dental Association

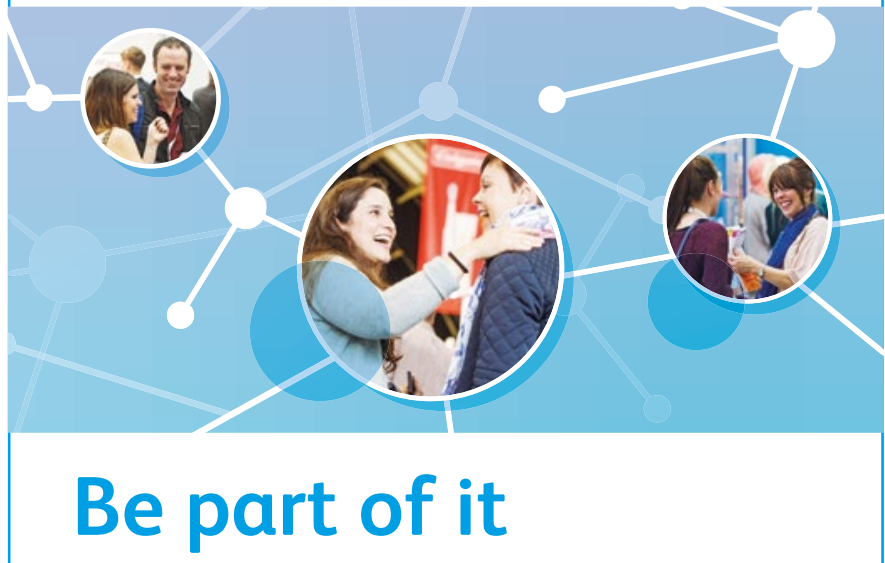

Have you considered getting involved?

The network is keen to hear from BDA members who would like to get involved and help make a difference in your local area.

bda.org/getinvolved 